\title{
Exploring the Potential of Chromium Reducing Bacillus sp. and there Plant Growth Promoting Activities
}

\author{
Ponmurugan Karuppiah ${ }^{1,2, *}$, Shyamkumar Rajaram² \\ ${ }^{1}$ Department of Microbiology, K.S.Rangasamy College of Arts and Science, Tiruchengode, Tamil Nadu, India \\ ${ }^{2}$ Department of Botany and Microbiology, College of Science, King Saud University, Riyadh, Saudi Arabia
}

\begin{abstract}
A large number of different microorganisms are commonly found in the soil including bacteria, fungi, actinomycetes, protozoa and algae of these bacteria are by far the most common type of soil microorganism possibly because they can grow rapidly and have the ability to utilize a wide range of substances as either carbon or nitrogen sources. Use of naturally occurring, free living bacterial species, which can protect and promote plant growth by colonizing and multiplying along the surface of the root and/or root cortex. In our present investigation was to study the plant growth promoting (PGP) activities and chromium reducing Bacillus sp. from rice fields of in and around Erode district. From 25 soil samples 63 different Bacllius sp. were isolated. Among the 63, eight Bacillus sp. (BA1 to BA 8) possess effective PGP activities. In eight different Bacillus isolates particularly (BA1, BA3, BA4 and BA6) exhibited maximum plant growth promoting and chromium reducing activities. In addition to these traits, plant growth promoting bacterial isolates must be rhizospheric competent, able to survive and colonize in the rhizospheric soil.
\end{abstract}

Keywords Bacillus, Chromium, Plant Growth Promoting Activities, Rhizospheric

\section{Introduction}

Agriculture is increasingly dependent on the use of chemical fertilizers, growth regulators and pesticides to increase yield. This dependency is associated with problems, such as environmental pollution, health hazards, interruption of natural ecological nutrient cycling and destruction of biological communities that otherwise support crop production. The use of bioresource to replace chemical pesticides, growth regulators and fertilizers is growing. In this context, plant growth promoting rhizobacteria (PGPR) are often novel and potential tools to provide substantial benefits to agriculture[1,2].

A large number of different microorganisms are commonly found in the soil including bacteria, fungi, actinomycetes, protozoa and algae[3] of these bacteria are by far the most common type of soil microorganism possibly because they can grow rapidly and have the ability to utilize a wide range of substances as either carbon or nitrogen sources. Use of naturally occurring, free living bacterial species, which can protect and promote plant growth by colonizing and multiplying along the surface of the root and/or root cortex of the inoculated plants is said to be one such safe and suitable alternative[4]. The organisms that establish positive interactions with plant roots and show observable benefits on

* Corresponding author:

ponmurugank@yahoo.com (Ponmurugan Karuppiah)

Published online at http://journal.sapub.org/microbiology

Copyright (C) 2011 Scientific \& Academic Publishing. All Rights Reserved the plant growth are collectively called as plant growth promoting rhizobacteria.

The rhizosphere of plants is a zone of intense microbial activity, and some bacteria from this zone, termed rhizobacteria exhibit active root colonization in the presence of the existing native micro flora. Rhizobacteria that exert beneficial an effect on plant development is also are referred to as PGPR[1], because their application is often associated with increased rates of plant growth. It is widely accepted that rhizosphere and rhizoplane microorganisms can influence plant growth and development. Some years later, the term plant growth promoting bacteria (PGPB) was proposed to designate rhizobacteria that enhands plant growth by other ways[5], plant growth promoting bacterial species including Pseudomonas, Azospirillum, Azotobacter, Klebsiella, Enterobacter, Alcaligens, Arthobacter, Bacillus andSerratia[6,7].

PGPR accounts for about $2-5 \%$ of the total the rhizobacteria involved in plant growth promotion[8]. Such PGPR use one or more direct or indirect mechanisms to improve the growth and health of plants. These mechanisms can be active simultaneously or independently at different stages of plant growth. Among these, P-solubilization, biological nitrogen fixation, improvement of other plant nutrients uptake, and phytohormone production like, Indole-3-acetic acid are some of the regulators that profoundly influence plant growth[9]. Moreover, biological control of plant pathogens and deleterious microbes, through the production of antibiotics, lytic enzymes, hydrogen cyanide, and siderosphores or through competition for nutrient and space can improve significantly 
plant health and promote growth as evidenced by increases emergence, vigor, and yield[8].

Heavy metal contamination has been on the rise in proportion to the pace of worldwide industrialization, leading to significant health problems and toxic effects on plant and microbial biodiversity[10]. Chromium compounds are being used in a wide variety of commercial processes like tanneries, metal cleaning and processing and alloy formation. Despite various treatments, procedures in use, unregulated disposal of the chromium containing effluent has led to the contamination sites by extracting metals from the soil and concentrating them in the above ground biomass leading to impaired metabolic activities and reduced plant growth[11]. Hence, the alternate way to reduce the toxicity of heavy metals in the plant could be using the rhizospheric microbes to enhance phytoremediation efficiency[12]. Microbes and plants have attracted attention because of the biotechnological potential site or the possible transfer of accumulated metals to higher plants and the diversion of heavy metals towards microbial metabolism and growth[13]. Several species of the genus Bacillus sp. are found predominantly in the rhizosphere of various crops for their ability to control plant diseases. The resistant endospore of Bacillus sp. provides toleration to heat and cold as well as to $\mathrm{pH}$ extremes, pesticides, fertilizers and heavy metals. In addition, the application of some Bacillus sp. has shown increased grain yield and plant biomass accumulation[14].

The inoculants bacteria used for these purpose mainly to the genus Bacillus. Bacillus sp. is spore-forming gram positive, rod shaped bacteria. They are highly tolerant of adverse ecological condition. Bacillus sp. comprises one of the most common soil bacteria groups and they are frequently isolated from the rhizospheres of plants. Because of their spore-forming ability, plant growth promoting Bacillus strains are readily adaptable to commercial formulation and field application[15].Therefore, it is necessary to develop efficient strains in field conditions, one possible approach is to explore in field conditions, one possible approach is to explore soil microbial diversity for PGPR having combination of plant growth promoting activities in terrestrial ecosystem and well adapted to particular soil environment.

So, keeping in view the above constraints, the present investigation was designed to screen heavy metal and plant growth promoting activities of Bacillus sp. from rice rhizospheres.

\section{Materials and Method}

\subsection{Collection of Sample}

Twenty five different rhizospheric soil samples were collected from rice field grown in Erode district of Tamil Nadu. The sample was collected in $1 \mathrm{~cm}$ depth and it was packed in a sterile polythene bag and labeled properly for further processing[16].

\subsection{Isolation of Bacillus Isolates}

The isolation of Bacillus sp. from soil samples, $1 \mathrm{~g}$ of soil sample was serially diluted in sterile distilled water, $0.1 \mathrm{ml}$ of soil suspension from $10^{-3}$ to $10^{-7}$ was spreaded on the nutrient agar plate. The plates were incubated for $24 \mathrm{hrs}$ at $37^{\circ} \pm 2^{\circ}$ $\mathrm{C}[17]$.

\subsection{Identification of Bacillus sp.}

The bacterial isolates were identified by using cultural, morphological and biochemical characteristics features described in Bergey's manual of determinative bacteriology[18] and stored at $4^{\circ} \mathrm{C}$ on slants and maintained through sub-culturing. The isolates were characterized by Gram staining, motility test, carbohydrate fermentation, oxidase test, catalase test, $\mathrm{H}_{2} \mathrm{~S}$ production and starch hydrolysis as per the standard methods[19].

\subsection{In vitro Screening of Multiple Plant Growth Pro- moting Activities of Bacillus sp.}

\subsubsection{Detection of Indole Acetic Acid (IAA) Production}

IAA production was detected by method as described by Brick et al.[20].Bacterial cultures were grown in nutrient broth amended with tryptophan $\left(20,40,60,80\right.$ and $\left.100 \mu \mathrm{g}^{-1}\right)$ for $72 \mathrm{hrs}$ at $28^{\circ} \mathrm{C}$ and then fully grown cultures were centrifuged at $3000 \mathrm{rpm}$ for 30 minutes. The supernatant $(2 \mathrm{ml})$ was mixed with two drops of orthophosphoric acid and $4 \mathrm{ml}$ of the salwaski reagent $(50 \mathrm{ml}, 35 \%$ perchloric acid, $1 \mathrm{ml}$ of $0.5 \mathrm{M} \mathrm{FeCl}_{3}$ solution). Development of pink colour indicates IAA production. Optical density was taken at $530 \mathrm{~nm}$ with the help of spectrophotometer.

\subsubsection{Hydrogen Cyanide (HCN) Production}

Bacillus isolates were screened for the production of hydrogen cyanide by adapting the method of Lorck[21]. Nutrient broth was amended with 4.4 glycine $1^{-1}$ and bacteria were streaked on modified agar plate. Whatman filter paper No. 1 soaked in $2 \%$ sodium carbonate in $0.5 \%$ picric acid solution was placed in the top of the plate. Plates were sealed with para-film and incubated at $28^{\circ} \mathrm{C}$ for 4 days development of orange to red colour indicated the production of hydrogen cyanide.

\subsubsection{Phosphate Solubilization}

Bacterial isolates were evaluated from the ability to solubilize inorganic phosphate. Pikovskaya's agar medium (HiMedia, Mumbai) containing calcium phosphate as the inorganic form of phosphate was used in this assay. A loopful of bacterial culture were placed on the plates and kept for incubation at $28^{\circ} \mathrm{C}$ for 7 days. The presence of clear zone around the bacterial colonies indicates the solubilization of phosphate.

\subsubsection{Heavy Metal Tolerance}

The selected bacterial isolates were tested for their resistance to heavy metals by agar dilution method. Freshly prepared Nutrient agar plates amended with soluble heavy 
metal chromium $(\mathrm{Cr})$ at various concentrations ranging from $50 \mu \mathrm{g}$ to $100 \mu \mathrm{g}$ were inoculated with bacterial cultures. Heavy metal tolerance was determined by the appearance of bacterial growth after incubating the plates at $28^{\circ} \mathrm{C}$ for $72 \mathrm{hrs}[22]$.

\subsubsection{Screening of Antifungal Activity}

The bacterial isolates tested for their antifungal activity by agar well diffusion method. Test fungi Fusarium sp., Pencillum sp. and Cercopsora sp. were grown on potato dextrose agar (PDA) slants. The spores were scraped and suspended in $10 \mathrm{ml}$ of sterile PDA broth. Diluted spore suspension $\left(10^{5}\right.$ $\mathrm{CFU}^{-1}$ ) of the fungi was spread on PDA plates $8 \mathrm{~mm}$ diameter wells were punched into the agar medium with sterile cork borer and filled with different volume $(50,75,100 \mu \mathrm{l})$ of bacterial culture. The plates were incubated for 5 days at $28 \pm 2^{\circ} \mathrm{C}$. The antifungal activity was evaluated by measuring the zone of inhibition[23].

\subsection{Statistical Analysis}

The results are reported as mean $\pm \mathrm{SD}$. The statistical variation in IAA production by Azotobacter isolates at different tryptophan concentration and antifungal activity against the test fungi were analyzed using an analysis of variance (ANOVA), following a mean separation according to the Tukey multiple range test. In all statistical analysis, $\mathrm{P}$ $<0.05$ was considered significant $[24,25]$.

\section{Results}

Rhizosphere soil along with roots and leaf samples from tea plants grown in different sites situated at three different altitudes in Erode district of Tamil Nadu, were collected and used for the isolation of Bacillus sp. using specific media. The attempts yielded 63 Bacillus isolates, as far as the sites at three different filed were concerned, samples collected at Erode district yielded 16 Bacillus isolates. Among the 63 Bacillus sp., 8 species of Bacillussp. were exhibited efficient plant growth promoting activities by screening methods.

The isolates were identified based on morphological and biochemical characteristics and were tested for their beneficial traits like ability to solubilization of insoluble inorganic phosphate, production of plant growth promoting substances and biocontrol potential. Efficient isolates selected based on the above characters were examined for their in vitro screening methods. The results obtained on these aspects are presented as follows.

\subsection{Isolation and Identification of Bacillus sp.}

On the basis of cultural, morphological and biochemical characteristics a total of 63 Bacillus isolates were identified from 25 rhizospheric soil samples as described in Bergey's Manual of Determinative Bacteriology[18]. Among the 63 isolates, 8 (BA1 - BA 8) were selected for further studies based on the efficiency of multiple plant growth promoting activities exhibited in preliminary studies (data not shown).
General features of the test isolates are illustrated in Table 1. The isolates observed as transparent, watery, mucoid, slimy colonies in Ashby's mannitol agar medium; gram negative rods; positive for catalase, indole, MR, VP, citrate, nitrate reduction; ferment glucose, lactose, mannitol, and sucrose producing both acid and gas; ability to hydrolyze the starch; and prototrophic for biotin.

Table 1. Morphological and cultural characteristics of Bacillusisolates from the rhizospheric soil of rice fields

\begin{tabular}{|c|c|}
\hline $\begin{array}{c}\text { Morphological and cultural } \\
\text { characterization }\end{array}$ & Bacillus species \\
\hline Number of isolates & Eight \\
\hline $\begin{array}{l}\text { Colony morphology on } \\
\text { Asbhy'smannitol agar }\end{array}$ & Cream, spreading, opaque \\
\hline Pigmentation & Transparent, milky \\
\hline Gram reaction, cell shape & Gram negative rods \\
\hline Growth on nitrogen free medium & Positive \\
\hline Biotin prototrophy & Positive $(90 \%)$ \\
\hline Motility & Motile \\
\hline Indole & Positive (100\%) \\
\hline Methyl red & Positive $(80 \%)$ \\
\hline Vogesproskaeur & Positive $(70 \%)$ \\
\hline Citrate & Positive (100\%) \\
\hline Catalase & Positive (100\%) \\
\hline Glucose & Acid and gas production $(100 \%)$ \\
\hline Lactose & Acid and gas production ( $80 \%)$ \\
\hline Mannitol & Acid and gas production (40\%) \\
\hline Sucrose & Acid and gas production (90\%) \\
\hline Nitrate reduction & Positive (100 \%) \\
\hline Starch hydrolysis & Positive (100\%) \\
\hline
\end{tabular}

Table 2. Multiple plant growth promoting activities of Bacillus isolates from the rhizospheric soil of rice fields

\begin{tabular}{|c|c|c|c|c|}
\hline $\begin{array}{c}\text { Bacillus } \\
\text { isolates }\end{array}$ & $\begin{array}{c}\text { Indole } \\
\text { acetic acid } \\
\text { production }\end{array}$ & $\begin{array}{c}\text { Ammonia } \\
\text { production }\end{array}$ & $\begin{array}{c}\text { Hydrogen } \\
\text { cyanide } \\
\text { production }\end{array}$ & $\begin{array}{c}\text { Phosphate } \\
\text { solubilization }\end{array}$ \\
\hline BA1 & +++ & +++ & +++ & +++ \\
\hline BA2 & ++ & + & - & - \\
\hline BA3 & +++ & ++ & + & +++ \\
\hline BA4 & +++ & +++ & +++ & +++ \\
\hline BA5 & + & + & - & ++ \\
\hline BA6 & +++ & + & +++ & +++ \\
\hline BA7 & - & + & ++ & + \\
\hline BA8 & + & - & ++ & + \\
\hline
\end{tabular}

BA - Bacillus isolates from rice tomato rhizospheric soil, + low colour intensity / zone formation ; ++ medium colour intensity / zone formation; +++ high colour intensity / zone formation; - no colour change / no zone formation

\subsection{Multiple Plant Growth Promoting Traits of Test Isolates}

Screening results of multiple PGP traits of 8 Bacillus sp. are depicted in Table 2. Out of eight isolates, four Bacillus isolates (BA1, BA3, BA4 and BA6) were showing multiple PGP activities in relation to indole acetic acid (IAA), ammonia, hydrogen cyanide and phosphate solubilization (Table 2). BA2, BA5, BA7 and BA 8 isolate neither producing 
ammonia nor solubilizing the phosphates. Among the eight only five Bacillus isolates were tolerant to mercury and zinc. Higher growth was noticed in BA1, BA4 and BA6 in chromium and mercury up to the concentration of $200 \mu \mathrm{gl}^{-1}$ (Table 3).

Table 3. Heavy metal tolerance among Bacillus isolates from Rhizospheric soil of rice fields grown on nutrient agar

\begin{tabular}{|c|c|c|c|c|}
\hline \multirow{2}{*}{ Bacillus isolates } & \multicolumn{5}{|c|}{ Chromium concentration $\left({\left.\mathbf{~} \mathbf{~ I ~}^{-1}\right)}^{-1}\right)$} \\
\cline { 2 - 5 } & 50 & 100 & 150 & 200 \\
\hline BA1 & +++ & +++ & +++ & +++ \\
\hline BA2 & + & + & + & + \\
\hline BA3 & +++ & ++ & + & + \\
\hline BA4 & +++ & +++ & ++ & ++ \\
\hline BA5 & + & + & + & + \\
\hline BA6 & +++ & +++ & +++ & ++ \\
\hline BA7 & + & + & + & - \\
\hline BA8 & ++ & + & + & + \\
\hline
\end{tabular}

BA-Bacillus isolates from rice rhizospheric soil+ low growth; ++ medium growth; +++ high growth; - no growth

\subsubsection{Quantitative assay of IAA Production}

A total of eight isolates of Bacillus sp. were tested for the quantitative estimation of IAA in the presence of different concentrations of tryptophan. With no addition of tryptophan, production of IAA was not observed. With the addition of tryptophan from 20 to $100 \mathrm{Mg}^{-1}$ the production of IAA was increased significantly from a minimum of $0.56-9.50 \mu \mathrm{g} \mathrm{l}^{-1}$. The maximum $9.50 \mu \mathrm{g} \mathrm{l}^{-1}$ IAA production was observed in BA6 at $100 \mu \mathrm{g} \mathrm{l}^{-1}$ of tryptophan concentration. The production of IAA was highest in the isolates of BA6 followed by BA1, BA2 and BA8. In BA3 and BA7, IAA production was detected only at higher concentration of tryptophan (Table
4).

Table 4. Production of indole acetic acid at differenttryptophan concentration by Bacillus isolates

\begin{tabular}{|c|c|c|c|c|c|c|}
\hline \multirow{2}{*}{$\begin{array}{c}\text { Bacillus } \\
\text { isolates }\end{array}$} & \multicolumn{7}{|c|}{ IAA production $\left(\boldsymbol{\mu \mathbf { g ~ } ^ { \mathbf { 1 } } )}\right.$} \\
\cline { 2 - 7 } & 0 & 20 & 40 & 60 & 80 & 100 \\
\hline BA1 & ND & 1.86 & 1.92 & 2.99 & 4.31 & 7.56 \\
\hline BA2 & ND & 1.59 & 2.68 & 3.80 & 4.89 & 6.96 \\
\hline BA3 & ND & ND & 0.07 & 0.18 & 0.96 & 1.22 \\
\hline BA4 & ND & 2.79 & 3.79 & 3.86 & 5.97 & 6.18 \\
\hline BA5 & ND & 0.69 & 0.77 & 0.84 & 0.91 & 0.99 \\
\hline BA6 & 0.56 & 2.79 & 5.86 & 7.96 & 8.23 & 9.50 \\
\hline BA7 & ND & ND & ND & ND & 0.50 & 0.61 \\
\hline BA8 & ND & 1.76 & 2.87 & 4.98 & 5.31 & 6.40 \\
\hline
\end{tabular}

ND - not detectable; BA - Bacillus isolates from rice rhizospheric soil

\subsubsection{Antiphytopathogenic Fungal Activity}

Antiphytopathogenic fungal activity of the ten Bacillus isolates was checked against Pencilliumsp., Cercospora sp. and F.oxysporum in SDA (Table 5). The antifungal activity of the Bacillus isolates tested varied with inhibition zones in diameter from 1.00 to $34.23 \mathrm{~mm}$. Isolates BA1, BA3, BA4 and BA6 induced larger inhibition zones showing their high antifungal activity and exhibiting broad-spectrum activities against test fungi compared to the other Bacillus isolates. Neither BA2 nor BA5 showed antifungal activity against the three test fungi. No antifungal activity was observed in isolates BA7 and BA8 at lower concentrations 50 and $100 \mu \mathrm{ll}^{-1}$ against test fungi (Table 5). Antiphytopathogenic fungal activity of the ten Bacillus isolates was increased significantly with the concentration of the culture suspension against Pencilliumsp., Cercospora sp. and F. oxysporum.

Table 5. Antiphytopathogenic fungal activity of Bacillus isolates againstAspergillusflavus, Cercospora sp. and Fusariumoxysporum ${ }^{\mathrm{a}}$

\begin{tabular}{|c|c|c|c|c|c|c|c|c|c|c|c|c|}
\hline \multirow{4}{*}{ BA } & \multicolumn{12}{|c|}{ Concentration of Bacillus suspension $\left(\mu 11^{-1}\right)$} \\
\hline & \multicolumn{3}{|c|}{50} & \multicolumn{3}{|c|}{100} & \multicolumn{3}{|c|}{150} & \multicolumn{3}{|c|}{200} \\
\hline & \multicolumn{12}{|c|}{ Zone of inhibition $(\mathrm{mm})$ of fungal pathogen } \\
\hline & $\mathrm{Pe}$ & Cs & Fo & $\mathrm{Pe}$ & Cs & Fo & $\mathrm{Pe}$ & Cs & Fo & $\mathrm{Pe}$ & Cs & $\mathrm{Pe}$ \\
\hline BA1 & 15.61 & 18.42 & 16.62 & 17.33 & 20.00 & 19.50 & 21.33 & 25.25 & 23.50 & 26.65 & 32.62 & 29.00 \\
\hline $\mathrm{BA} 2$ & 1.10 & ND & ND & 3.00 & 2.25 & 2.15 & 3.45 & 2.60 & 2.75 & 3.51 & 2.66 & 2.80 \\
\hline BA3 & 12.25 & 15.10 & 13.10 & 16.45 & 22.68 & 19.00 & 23.45 & 28.45 & 25.00 & 29.62 & 34.23 & 31.00 \\
\hline BA4 & 14.50 & 19.50 & 17.00 & 18.65 & 23.65 & 20.65 & 21.35 & 29.26 & 24.33 & 23.26 & 32.35 & 28.65 \\
\hline BA5 & ND & ND & ND & ND & ND & ND & ND & ND & ND & ND & ND & ND \\
\hline BA6 & 12.32 & 17.65 & 15.52 & 14.55 & 21.00 & 18.83 & 18.17 & 24.33 & 20.67 & 24.17 & 30.35 & 28.75 \\
\hline BA7 & $\mathrm{ND}$ & ND & ND & 1.00 & ND & ND & 2.23 & 1.00 & 1.89 & 2.65 & 2.45 & 3.45 \\
\hline BA8 & $\mathrm{ND}$ & ND & ND & ND & ND & ND & $\mathrm{ND}$ & $\mathrm{ND}$ & ND & ND & ND & $\mathrm{ND}$ \\
\hline
\end{tabular}

BA - Bacillus isolates from rice rhizospheric soilND - Not detected; Pe - Pencilliumsp; Cs - Cecospora sp.; Fo - Fusariumoxysporum 


\section{Discussion}

Understanding the dynamics of root colonization by specific microbial components of the rhizoplane and rhizosphere is basic to the development of biological control of soil borne pathogens and the effective use of beneficial microorganisms to enhance plant growth[1]. Plant rhizophere is known to be preferred ecological niche for various types of PGPR due to rich nutrient availability. The three main intrinsic characteristics of PGPR must be: (i) able to colonize the root, (ii) survive and multiply in microhabitats associated with the root surface, in competition with other microbiota, at least for the time needed to express their plant promotion/protection activities, and (iii) promote plant growth[26-29]. Further, exploration and evaluation of the isolates exhibiting multiple PGP traits on soil-plant system is needed to uncover their efficacy as effective PGPR[28,29]. In the present investigation multiple PGP activities were found in four Bacillus isolates (BA1, BA3, BA4 and BA6) out of eight isolates screened from rice growing rhizospheric soil.

Based on earlier reports[30-34] eighty percent of microorganisms (Azospirillum, Pseudomonas, Xanthomonas, and Rhizobiumas well as Alcaligenesfaecalis, Enterobacter cloacae, Acetobacterdiazotrophicus,A.chroococcumand Bradyrhizobiumjaponicum)isolated from the rhizosphere of various crops have the ability to produce IAA which help in stimulating plant growth. IAA production was detected in all the test isolates of Bacillus sp. The Bacillus isolates BA4, BA6, BA1 and BA3 produced higher amount of IAA, but in BA7 and BA8 the production was detected at higher concentration of tryptophan. Further, there was an increase in the level of IAA with the increasing concentration of tryptophan $\left(10-100 \mu \mathrm{gl}^{-1}\right)$ as evidenced by Ahmed et al.,[29].

Another important traitof PGPR, that may indirectly influence the plant growth, is the production of ammonia and solubilization of phosphate. However, ammonia production and phosphate solubilizationobserved frequently in Bacillus sp. about $60-70 \%$ than the other isolates[35]. A considerably higher concentration of phosphate solubilizing bacteria is commonly found in the rhizosphere soil[36-38,34]. Further, it was found that all the isolates of Bacillus obtained from rice soils are ammonia producers as well as solubilizing the phosphates, except BA8, BA2 and BA7, have good prospects to improve plant growth especially in soil with large amount of precipitated phosphate.

As per earlier reports[39-41]Azotobacter sp. protect several plants from root disease caused by soil borne fungi through $\mathrm{HCN}$ and siderophore production. Hydrogen cyanide production by Azotobacter isolates were about $60 \%$ for the inhibition of phytopathogens in the soil[34,29]. Most of the Bacillus sp. isolated (BA1, BA3, BA4, BA6, BA7 and BA8) from soils of vegetable plants are producing $\mathrm{HCN}$ as well as siderophore and act as potent antifungal agent. Synergistic interaction of these two with other metabolites may further function as stress factors including local and systematichost resistance[42] that led for the suppression of the root pathogens. Out of eight Bacillus isolates, four isolates (BA1, BA3, BA4 and BA6) were exhibiting high antifungal activity against Pencilliumsp, Cercospora sp. and F. oxysporum. The antifungal activity of the screened Bacillus isolates was concentration dependent.

Bacillus sp. had developed the mechanisms to cope with a variety of heavy metals for their survival in the rhizosphere of vegetable ecosystem[34] and can be used to reduce the toxicity of the metal or increase its bioavailability[10]. It was observed that few Bacillus rhizobacteria tolerate the $\mathrm{Zn}$ and $\mathrm{Hg}$ metal concentration to the level of $100-200 \mu \mathrm{gl}^{-1}$ and exhibiting a multiple PGPR activities like IAA, $\mathrm{HCN}, \mathrm{NH}_{3}$ production and siderophores. This was evidenced in our study with Bacillus isolates BA1, BA3, BA4 and BA6. It was also apparent that most of the cultures of PGPR isolated from vegetable rhizosphere were tolerant to elevated levels of heavy metals that may decrease heavy metal toxicity and increase the PGPR activities for the plant growth [43].

\section{Conclusions}

The isolation of PGPR from different sources opens new doors to deign strategies for improving the efficacy of biocontrol agents. Identification of key antimicrobials produced by superior agents can be exploited for streamlining strain discovery by targeting selection of new isolates that carry relevant biosynthetic genes. Determination of the role of edaphic parameters favourable for disease suppression, particularly those that stimulate antibiotic production and activity, can be exploited by targeting inoculants for soils that are more likely to support biocontrol. Biocontrol with plant growth promotion helps increasing the vegetative yield and thereby increasing crop yield.

\section{ACKNOWLEDGEMENTS}

The authors are grateful to the Management and Principle of the K.S.Rangasamy College of Arts and Science, Tiruchengode -637215 , Tamil Nadu, for providing financial support necessary facilities.

\section{REFERENCES}

[1] Kloepper, J.W., Schroth, M.N., and Miller, T.D., 1980, Effects of rhizosphere colonization by plant growth promoting rhizobacteria on potato plant development and yield., Ecology and Epidemiology, 70 (11), 1078-1082

[2] Enebak, S.A., Wie, G., and Kloepper, J.W., 1998, Effects of plant-growth-promoting rhizobacteria on loblolly and slash pine seedlings., Forest Science, 44, 139-144

[3] E.A. Paul, and F.E. Clark, Soil Microbiology and Biochemistry, Academics Press, San Diego, CA, 1996

[4] Mishra, P.K., Mishra, S., Selvakumar, G., Bisht, S.C., Kundu, 
S., Bisht, J.K., and Gupta, H.S., 2008, Characterization of a psychrotrophic plant growth promoting Pseudomonas PGERs17 (MTCC 9000) isolated from North Western Indian Himalayas., Annals of Microbiology, 58 (4), 1-8.

[5] Bashan, Y. 1998. Inoculants of plant growth-promoting bacteria for use in agriculture.,Biotechnology Advances, 16, 729-770.

[6] Glick, B.R., 1995, The enhancement of plant growth by free living bacteria., Canadian Journal of Microbiology, 41, 109-114

[7] Han, H.S., and Lee, K.D., 2005, Plant Growth Promoting Rhizobacteria effect on antioxidant status, photosynthesis, mineral uptake and growth of Lettuce under soil salinity., Research Journal of Agriculture and Biological Sciences, 1(3), $210-215$

[8] H. Antoun, and J.W. Kloepper, Plant growth promoting rhizobacteria (PGPR). In Encyclopedia of Genetics. Academic Press, New York. Edited by Brenner S, Miller JH, pp. 1477-1480, 2001

[9] Zaidi, Khan, M.S., Ahemad, M., Oves, M., 2009, Plant growth promotion by phosphate solubilizing bacteria., ActaMicrobiologica et ImmunologicaHungarica, 56(3), 263-284

[10] Denton, B., 2007,Advances in Phytoremediation of heavy metals using plant growth promoting bacteria and fungi., Electronic Journal Basic Biotechnology, 3,1- 5

[11] Jiang, C.Y., Sheng, X.F., Quan, M., and Wang, Q.Y., 2008, Isolation and characterization of a heavy metal resistant Burkholderia sp. from heavy metal contaminated paddy field soil and its potential in promoting plant growth and heavy metal accumulation in metal polluted soil., Chemosphere, 72, $157-164$

[12] Park, M., Kim, C., Yang, J., Lee, H., Shin, W., Kim, S., and $\mathrm{Sa}, \mathrm{T}$., 2005, Isolation and characterization of diazotrophic growth promoting bacteria from rhizosphere of agricultural crops of Korea. Microbiology Research, 160, 127-133

[13] Polti, M.A., Amoroso, M.J., and Abate, C.M., 2007, Chromium (VI) resistance and removal by actinomycetes strains isolated from sediments., Chemosphere, 67, 660-667

[14] Pal, V., and Jalali, I., 1998, Rhizosphere bacteria for biocontrol of plant diseases. Indian Journal of Microbiology, 38, $187-204$

[15] Liu, Z., and Sinclair, J.B., 1993, Colonization of soybean roots by Bacillus megateriumB153-2-2., Soil Biology and Biochemistry, 25, 849-855

[16] Ahmad, F., Ahmad, I., and Khan, M.S., 2005, Indole Acetic Acid Production by the Indigenous Isolates of Azotobacterand Fluorescent Pseudomonas in the Presence and absence of Tryptophan., Turkish Journal of Biology, 29, 29-34

[17] Farah, A., Iqbal, A., and Khan, M.S., 2006, Screening of free-living rhizospheric bacteria for their multiple plant growth promoting activity, Microbiology Research, 163, 173-181

[18] J.G. Holt, N.R. Krieg, P.H.A. Sneath, J.T. Staley and S.T. Williams, In: Bergy's Manual of Determinative Bacteriology, 9th ed., Williams and Wilkins Pub., MD: USA, 1994

[19] J.C. Cappuccino and N. Sherman, In: Microbiology: A La- boratory Manual, 3rd ed., Benjamin/Cummings Pub.Co., New York, 1992

[20] Brick, J.M., Bostock, R.M., and Silverstone, S.E., 1991, Rapid in situ assay for indole acetic acid production by bacteria immobilized on nitrocellulose membrane., Applied and Environmental Microbiology, 57,535-538

[21] Lorck, H., 1948, Production of hydrocyanic acid by bacteria., Plant Physiology, 1, 142-146

[22] Summers, A.O., and Silver, S., 1972. Mercury resistance in a plasmid bearingstrains of Escherichia coli. Journal of Bacteriology, 112, 1228-1236

[23] Mehmood, Z., Ahmad, I., Mohammad, F., and Ahmad, S., 1999, Indian medicinal plants: a potential source of anticandidal drug., Pharmaceutical Biology, 37, 237-242

[24] SAS Institute., 1988, SAS Users Guide: SAS/STAT, release 6.03. SAS Institute, Cary, NC

[25] G.W. Snedecor, and W.G. Cochran, Statistical methods, 8th ed., Iowa State University Press, Iowa, 1989

[26] Espinosa-Urgel, M., Roberto Kolter, and Juan-Luis Ramos., 2002, Root colonization by Pseudomonas putida: love at first sight., Microbiology, 148, 341- 343

[27] Gamalero, E., Trotta, A., and Berta, G., 2004, Impact of two fluorescent pseudomonads and an arbusculermycorrhizal fungus on tomato plant growth root architecture and phosphate acquisition., Mycohorriza, 14, 185-192

[28] Nivedhitha, V.R., Shwetha, B., Deepa, F., Dsouza, D.D., Manojkumar, N.H., and RaghavendraRao, B., 2008, Plant growth promoting microorganisms (PGPMs) from bamboo rhizosphere. JournalofAdvanced Biotechnology,7(1), 33-35

[29] Ahmad, F., Ahmad, I., and Khan M.S., 2008, Screening of free-living rhizospheric bacteria for their multiple plant growth promoting activities.,Microbiology Research, 63(2), 173-81

[30] N.S. SubbaRao, Soil Microbiology: Soil microorganisms and plant growth, 8th ed., Science Publishers, Inc. USA, 1999

[31] Xie, H., Pasternak, J.J., and Glick, B.R., 1996, Isolation and characterization of mutants of the plant growth promoting rhizobacteriumPseudomonasputida GR12-2 that over produce indole acetic acid., Current in Microbiology,32, 67-71

[32] Patten, C.L., and Glick, B.R., 2002, Role of Pseudomonasputidaindole acetic acid in development of the host plant root system., Applied and Environmental Microbiology, 68, 3795-3801

[33] Husen, E., 2003, Screening of soil bacteria for plant growth promotion activities in vitro., Indonesian Journal of Agricultural Science, 4(1), 27-31

[34] Joseph, B., PatraRanjan, R., and Lawrence, R., 2007, Characterization of plant growth promoting rhizobacteria associated with chickpea (Cicerarietinum. L)., International Journal of Plant Production, 2, 141-151

[35] Lakshminaryana, K., Bela, S., Sandhu, S.S., Kumari, P., Narula, N., and Sheoran, R.J., 2000, Analogue resistant mutants of Azotobacterchroococcumderepressed for nitrogenase activity and early ammonia excretion having potential as inoculants for cereal crops., Indian Journal of Experimental 
Biology,38, 373-378

[36] Suh, J. S., Lee, S. K., Kim, K. S., and Seong, K. Y., 1995, Solubilization of insoluble phosphates by Pseudomonasputida, Penicillium sp. and Aspergillusniger isolated from Korean soils., Journal of Biotechnology, 28(3),278-286

[37] Whitelaw, M.A., Harden, R.J., and Helyar, K.R., 1999, Phosphate solubilisation in culture by the soil fungus Penicilliumradicum., Soil Biology and Biochemistry, 31, 655-665

[38] Rodriguez, H., Frag-R., Gonzalez, T., and Bashan, Y., 2006, Genetics of phosphate solubilization and its potential applications for improving plant growth-promoting bacteria., Plant Soil,287, 15-21

[39] Carlot, M., Giacomini, A., and Casella, S., 2002,Aspects of plant-microbe interactions in heavy metal polluted soil., Ac-
taBiotechnologica, 22, 13-20

[40] Barea, J.M., Pozo, M.J., Azcón, R., Azcón-Aguilar, C., 2005b, Microbial co-operation in the rhizosphere., Journal of Experimental Botany, 56, 1761-1778

[41] Zahir, A.Z., Arshad, M., FrankenbergerJr.W.T., 2004, Plant growth promoting rhizobacteria: Applications and Perspectives Agriculture., Advanced in Agronomy, 81, 97-168

[42] Dave, B.P., and Dube, T.E., 2000, Regulation of siderophore production by iron Fe (III) is certain fungi and fluorescent Pseudomonads., Indian Journal of Experimental Biology, 38,297-299

[43] Burd, G.I., Dixon, D.G., and Glick, B.R., 2000, Plant growth promoting bacteria that decrease heavy metal toxicity in plants.,CanadianJournal of Microbiology,46, 237-245. 